\title{
The Effect of Integrated Yoga on Cognitive Functions in Pregnant Women - A Randomised Controlled Trial
}

\section{Satyapriya Maharana ${ }^{1 *}$, Sanjib Patra ${ }^{2}$, Raghuram Nagarathna ${ }^{3}$, Padmalatha Venkataram $^{4}$ and Hongasandra Ramarao Nagendra ${ }^{5}$}

${ }^{1}$ Associate Professor, Division of Yoga and Life Sciences, SVYASA, Bengaluru, India

${ }^{2}$ Associate Professor, Department of Yoga, Central university of Rajasthan,

Bandarsindri, Ajmer, Rajasthan, India

${ }^{3}$ Chief Medical Officer, Arogyadhama, SVYASA, Bengaluru, India

${ }^{4}$ Consultant Obstetrician and Gynecologist, Rangadurai Hospital and Maiya

Multispecialty Hospital, Bengaluru, India

${ }^{5}$ Chancellor, SVYASA, Bengaluru, India

*Corresponding Author: Satyapriya Maharana, Associate Professor, Division of Yoga and Life Sciences, SVYASA, Bengaluru, India.
Received: October 28, 2021

Published: December 30, 2021

(C) All rights are reserved by Satyapriya

Maharana., et al.

\begin{abstract}
Background: Heightened stress and anxiety during pregnancy can be potential causes of many complications, including impairment of higher brain cognitive functions. Since, there are no studies that address this complication holistically and yoga is found to be beneficial in many lifestyles related diseases.

Aim: To investigate the impact of integrated yoga (IY) intervention on cognitive functions and anxiety among pregnant women.

Methods: This was a prospective randomized two armed active control design with supervised practices for both groups. Ninety-six pregnant women (20 to 35 years of age, between 18 and 20weeks of gestation), satisfying the selection criteria were randomized to yoga (50) and control groups (46). Yoga group practiced specific set of integrated yoga and control group, standard antenatal exercises. Pre and post assessments were done at the time of recruitment and at $36^{\text {th }}$ week.

Results: A significant increase in the scores of all variables were observed such as 'Fluency test', (phonemic fluency, category fluency and design fluency, indicators of general verbal functioning, $\mathrm{p}<0.001$ ), 'Stroop test' (Stroop effect, measuring brain's information processing ability, $\mathrm{p}<0.001)$ and 'Pregnancy related anxiety questionnaire' $(\mathrm{p}<0.001)$ in yoga group. Mann Whitney $U$ testsshow that the magnitude of change in yoga group was higher than that observed in control group.

Conclusion: This study showed that integrated antenatal yoga starting from second trimester helps in improving cognitive functions and reducing anxiety, suggestive of a positive impact of yoga in promoting better information processing in prefrontal cortex.
\end{abstract}

Keywords: Pregnancy; Cognitive Function; Prefrontal Cortex; Anxiety; Integrated Yoga Module

\section{Introduction}

Advances in science, technology and management have offered many tools to obstetric practice. Systematic implementation of these tools in antenatal health programme has saved many lives. But, there are many pregnancy complications which are on the rise. Approximately 30 percent of pregnancies in United States experi- ence at least one obstetric complication [1]. Cognitive impairment during pregnancy is one such problem that is being recognized in recent days. There are many well designed RCTs that have reported impairment in cognitive functions during pregnancy. De Groot., et $a l$. showed that during normal early pregnancy, performance on intentional learning and retrieval from semantic memory were lower but the speed of information processing was not different from a 
matched group of non-pregnant women [2]. Similar observations of impaired cognitive functions (focused/divided attention and memory) have been reported in the third trimester of pregnancy [3]. Onyper., et al. reported lower scores on verbal fluency in pregnant women compared to non-pregnant women [4]. A research attempt in pregnant women reported selective impairment of cognitive (memory) tasks that depend on prefrontal cortex [5].

Cognitive functions include three major components namely attention/concentration, memory and executive functions. Fluency and response inhibition are measures related to Prefrontal executive functions. Imaging studies have demonstrated that verbal fluency activates frontal lobes, particularly the prefrontal cortex in the language dominant area of the hemisphere, while design fluency produces bilateral activation of prefrontal lobes [6]. Lesion studies also have confirmed these observations that there were deficits in phonemic fluency due to the damage to the left frontal lobe [7]. The category fluency involves the temporal lobe [8] while the design fluency is mediated by the right frontal and right frontal central regions [9]. Thus, the three components of Stroop fluency such as verbal, design and phonemic fluency activate frontal lobe directly or indirectly whereas temporal lobe is involved during Category fluency [10]. The prefrontal areas are essential for response inhibition. Cipolotti., et al. in their lesion studies showed impaired performance in response inhibition (Stroop colour word test) when they damaged the bilateral superior medial prefrontal regions [11]. Patients with bilateral superior medial prefrontal damage showed increased errors and slowness in incongruent condition wherein the colour name had to be read when it was printed in the ink of another color [12]. Imaging studies using PET have shown activation of the anterior right hemisphere regions and the medial frontal structures in the Stroop task [13]. The anterior cingulate is active during responses to the incongruent stimuli [14].

Yoga as a stress relieving holistic practice has been found to be beneficial in many life style related diseases. Documented results show: better endothelial function in patients with Coronary Artery disease [15], better psychosocial functioning and quality of life in cancer survivors [16] and reduced depression and anxiety [17]. Recently yoga was found to be beneficial for distressed women [18], reducing perceived stress [19] and more over yoga educational programme helped the pregnant women in reducing stress, anxiety, labour pain and increase delivery confidence [20]. To date there are several studies that have looked at the beneficial effects of yoga during normal pregnancy. A recent article has reviewed the benefits of yoga during pregnancy [21] and recommended its implementation in antenatal clinics. The beneficial effects of antenatal yoga include: shorter durations of labour [22] reduced rate of assisted vaginal deliveries, lesser pain scores with increased sense of satisfaction [23], improved sleep efficiency [24] and better autonomic adaptability in third trimester [25]. There are studies that have shown benefits of yoga when combined with other mind-body therapies during antenatal period [26].

Several studies on normal healthy volunteer's point to improvement in cognitive functional abilities after different techniques of yoga such as cyclic meditation or pranayama or integrated yoga. To our knowledge there is no study that has looked at the cognitive functions in pregnant women following yoga. The present study was planned to assess the effect of integrated antenatal yoga on cognitive functions in normal pregnancy with the hypothesis that there will be improvement in cognitive abilities after the practice of specific modules of antenatal yoga.

\section{Materials and Methods}

\section{Participants}

The 'G power' software was used with alpha $=0.05$, power $=0.8$ and Cohen's effect size calculated as 0.54 to derive a sample size of 44 for each arm. No major studies on the impact of yoga intervention on cognitive functions during pregnancy could be found. Hence the mean and SD values of an earlier study 2[6] on neurocognitive functioning during pregnancy was used to calculate the effect size. One hundred five women in their 18th to 20th weeks were inducted.

\section{Randomization}

Participants were randomized into two groups such as experimental (yoga) and control (antenatal exercise) using a computer generated (www.randomizer.com) random number table. Post the baseline assessments, participants were assigned to one of the groups by the researchers (unblinded) using the randomization list.

All of the 107 cases were enrolled from a pool of 228 subjects admitted for antenatal care at Maiya Multi-Specialty Hospital in South Bengaluru, India. Inclusion criteria were: (a) normal pregnancy in gestational age between 18 and 20 weeks, (b) prime gravidae (c) multigravidae with at least one living child. Those with maternal physical and psychological abnormalities, fetal abnormalities, assisted pregnancy, multiple pregnancies or previous exposure to yoga or vigorous physical exercises were excluded. 
The study was approved by the Institutional ethical committee of the yoga university (SVYASA) and a signed informed consent was obtained from all participants before randomization.

\section{Design}

The present study is a prospective randomized two armed active control design with supervised practices for yoga and active control groups. The subjects were allocated to two groups (yoga and control) after obtaining the signed informed consent from the subjects. The subjects were assessed at the time of recruitment (1820 weeks) and at $36^{\text {th }}$ week. Yoga group practiced a set of integrated yoga designed for pregnancy and the control group practiced standard antenatal exercises. Trained certified instructors taught the practices ( 2 hours/session) 3 days/week for one month at the center in batches of 4 to 10 . The subjects were asked to practice the same at home regularly during the other four days of the week and also after the month long training, by using a prerecorded instruction cassette for one hour. Refresher classes of 2 hours were conducted for both groups each time they came for their antenatal obstetric assessment. Compliance and follow-up was ensured over phone calls and maintenance of a daily activity diary.

\section{Masking}

As this was an interventional study, we could not blind the participants or the trainer. The team who taught the intervention was not involved in the assessments. The statistician was blinded to the source of the data. The timing of the classes for the two groups was staggered to avoid interaction and exchange of techniques between participants of the two groups.

\section{Intervention - yoga sessions}

Specific set of integrated approach of yoga therapy (IAYT) was developed by a team of experts for improving the cognitive functions during pregnancy. The knowledge from traditional scriptures (Patanjali yoga sutras, yoga Vasistha, bhagavadgita. Etc.) was used to develop this practices that included techniques to improve mental equilibrium and blissful rest. Different sets of practices for the three trimesters were prepared (Table 1). The number of asanas (physical postures) went on reducing with increasing gestational age. Asanas were practiced as per the principles based on Patanjali yoga sutras. Focused internal awareness (eyes closed) of the parts of the body and relaxation while maintaining the final posture helps in improving the flexibility of the joints, strengthening of the muscles and a calm state of mind. The breathing techniques (Pranayama) were focused on conscious prolongation of the breathing cycle that helps in improving the vital capacity and balance of vital energy (prana). The IAYT program also included different techniques of relaxation in supine posture. Meditation (dhyanaanddharana) using 'OM' mantra, was an important component of the program that helped in promoting concentration, alertness and inner calm [27].

\begin{tabular}{|c|c|c|c|c|}
\hline \multirow{6}{*}{ Yoga group } & & & $2^{\text {nd }}$ trimester & $3^{\text {rd }}$ trimester \\
\hline & Lectures (15min) & & & \\
\hline & Breathing Exercises (10 min) & $\begin{array}{l}\text { 1.Hands in and out breathing } \\
\text { 2.Hands stretch breathing } \\
\text { 3.Ankle stretch breathing } \\
\text { 4. Tiger breathing } \\
\text { 5. Bridge posture breathing }\end{array}$ & $\begin{array}{l}\text { Yes } \\
\text { Yes } \\
\text { Yes } \\
\text { Yes } \\
\text { Yes }\end{array}$ & $\begin{array}{l}\text { Yes } \\
\text { Yes } \\
\text { Yes } \\
\text { No } \\
\text { No }\end{array}$ \\
\hline & Asana Postures (15min) & $\begin{array}{c}\text { Standing Asanas } \\
\text { 1. Tree pose } \\
\text { 2. Lateral Arc Pose } \\
\text { 3. Triangle pose } \\
\text { Sitting Asanas } \\
\text { 4. The Ankle Posture } \\
\text { 5. Spine twist pose } \\
\text { 6. Sage pose } \\
\text { 7. Bound Ankle Pose } \\
\text { 8. Sit with legs apart } \\
\text { 9. Garland pose } \\
\text { Supine Asanas } \\
\text { 10. Half shoulder stand } \\
\text { 11. Folded leg lumbar stretch }\end{array}$ & $\begin{array}{l}\text { Yes } \\
\text { Yes } \\
\text { Yes } \\
\text { Yes } \\
\text { Yes } \\
\text { No } \\
\text { No } \\
\text { No } \\
\text { No } \\
\\
\text { Yes } \\
\text { Yes }\end{array}$ & $\begin{array}{l}\text { Yes } \\
\text { Yes } \\
\text { Yes } \\
\text { Yes } \\
\text { No } \\
\text { Yes } \\
\text { Yes } \\
\text { Yes } \\
\text { Yes } \\
\\
\text { No } \\
\text { Yes }\end{array}$ \\
\hline & Pranayama and Meditation (10 min) & $\begin{array}{l}\text { 1. Sectional breathing, } \\
\text { 2. Naadisuddhi, } \\
\text { 3. Sheetali,bharamari } \\
\text { 4. Nadanusandhana } \\
\text { 5. Om Meditation }\end{array}$ & $\begin{array}{l}\text { Yes } \\
\text { Yes } \\
\text { Yes } \\
\text { Yes } \\
\text { Yes }\end{array}$ & $\begin{array}{l}\text { Yes } \\
\text { Yes } \\
\text { Yes } \\
\text { Yes } \\
\text { Yes }\end{array}$ \\
\hline & Deep relaxation technique (10 $\mathrm{min})$ & & & \\
\hline
\end{tabular}




\begin{tabular}{|c|c|c|c|c|}
\hline \multirow{5}{*}{$\begin{array}{l}\text { Control } \\
\text { group }\end{array}$} & Lectures (15min) & & & \\
\hline & Loosening Exercises (10 min) & $\begin{array}{l}\text { 1. Twisting } \\
\text { 2. Forward and backward bend } \\
\text { 3. Side bending } \\
\text { 4. Calf-raise } \\
\text { 5. Hamstring stretch } \\
\text { 6. Lateral Pulls- up and down } \\
\text { 7. Calf extension } \\
\text { 8. Hip Abduction }\end{array}$ & $\begin{array}{l}\text { Yes } \\
\text { Yes } \\
\text { Yes } \\
\text { Yes } \\
\text { Yes } \\
\text { Yes } \\
\text { Yes } \\
\text { No }\end{array}$ & $\begin{array}{l}\text { Yes } \\
\text { No } \\
\text { Yes } \\
\text { Yes } \\
\text { Yes } \\
\text { No } \\
\text { No } \\
\text { Yes }\end{array}$ \\
\hline & Antenatal Exercises (15 min) & $\begin{array}{c}\text { Standing exercises. } \\
\text { 1. Thigh stretch } \\
\text { 2. Push-up and Down } \\
\text { 3. Pulls Downs } \\
\text { 4. Low-Back lift } \\
\text { Sitting Exercises. } \\
\text { 5. Inner thigh Stretch } \\
\text { 6. Calf stretch } \\
\text { 7. Dips } \\
\text { 8. Squatting } \\
\text { 9. Hip abduction } \\
\text { 10. Shoulder-chest stretch } \\
\text { 11 Neck and upper back stretch } \\
\text { 12. Seated Rowing } \\
\text { 13. Oblique curis } \\
\text { 14. Kick backs } \\
\text { 15. Pelvic floor exercise } \\
\text { Supine exercise } \\
\text { 16. Pelvic Tilt }\end{array}$ & $\begin{array}{l}\text { Yes } \\
\text { Yes } \\
\text { Yes } \\
\text { Yes } \\
\text { Yes } \\
\text { Yes } \\
\text { Yes } \\
\text { No } \\
\text { Yes } \\
\text { Yes } \\
\text { Yes } \\
\text { Yes } \\
\text { Yes } \\
\text { Yes } \\
\text { Yes } \\
\text { Yes }\end{array}$ & $\begin{array}{c}\text { Yes } \\
\text { Yes } \\
\text { No } \\
\text { No } \\
\text { Yes } \\
\text { Yes } \\
\text { No } \\
\text { Yes } \\
\text { Yes } \\
\text { Yes } \\
\text { Yes } \\
\text { Yes } \\
\text { Yes } \\
\text { Yes } \\
\text { Yes } \\
\text { Yes }\end{array}$ \\
\hline & Slow Walking & & & \\
\hline & Supine Rest & & & \\
\hline
\end{tabular}

Table 1: Yoga and exercise intervention group practice details (60 minutes daily).

Intervention - control group

The control group practiced simple stretching exercises (Table 1) for one hour as approved by the Executive Council of the society of Obstetrician and Gynecologists of Canada, and by the board of directors of the Canadian society for exercise physiology [28]. The initial part of each session was planned to provide conventional information on healthy diet, regular exercises, and a right attitude for prevention of stress.

\section{Assessments}

\section{Fluency test}

Fluency refers to mental flexibility and it is measured in both verbal and visual modalities. Spontaneous flexibility requires a ready flow of ideas and answers, often in response to a single question. It is a measure of the intrinsic capacity to generate alternatives in a regulated manner [29].
Verbal fluency refers to the capacity to generate new words in a regulated manner. Asking the subject to generate words beginning with a consonant is called Phonemic fluency whereas to generate words belonging to a category that imposes regulation is Category fluency.

\section{Phonemic fluency}

Controlled oral word association test is a measure of phonemic fluency. The subject generates words based on the phonetic similarity of words. The subject generates words beginning with the letters F, A, S. Proper nouns and names of numbers should be excluded. The same word should not be repeated with a different suffix. In our adaptation, for those subjects who did not know the English language, they were asked to generate words in their mother tongue, commencing with the consonants "Ka", "Pa", "Ma". These consonants were chosen as they were effective in eliciting words in an earlier study carried out in NIMHANS, Bengaluru [30]. 
Procedure

The subject is seated and told that she has to generate words beginning with a consonant that will be provided by the tester. $\mathrm{A}$ practice trial is given with the consonant other than the ones used in the test. The subject is asked to generate words for one minute for each consonant; for example, a word starting with the consonant ' $F$ ' and ending with ' $S$ '. After the subject has understood the task, the test is administered as three trials of one minute each. After each one-minute trial, the subject is given a short pause before commencing the next trial.

\section{Scoring}

The total number of acceptable new words produced in one minute is noted for each trial. The average of 3 trials forms the score. Duration of the test was approximately 5 minutes.

\section{Category Fluency}

Category fluency measured by 'Animal Names Test' is another form of verbal fluency. Incategory fluency, unlike in phonemic fluency, looksat the content of the words, rather than the phonetic similarity of the words. In this test, the subject generates words that belong to a particular semantic category. The Animal names test [31] requires the subjects to generate names of animals for one minute. The subjects are asked to generate the names of as many animals as possible in one minute. They are asked to exclude the names of birds, snakes and fish.

The total number of new words generated forms the score. Approximate duration of this test was three minutes.

\section{Design fluency test}

The Design Fluency Test [32] measures the ability to produce novel designs. It is a means of testing the visual fluency. Visual fluency is the capacity to generate new visual forms and it measures the regulation of thinking with visual imagery and visual forms. The designs should not represent actual objects or nameable abstract forms such as geometric designs. Therefore, the subject is asked to produce new forms and not reproduce these forms from memory.

The subjects are asked to draw as many new forms as possible in a given period of time. There are two conditions to this test: Free and Fixed conditions. In the Free condition, the subject is given 5 minutes to draw new designs. In the Fixed condition, the subject draws novel designs with the restriction that only four straight or curved lines may be used per design within four minutes. In both tests, the instructions include: the drawings should not be geometric forms or similar to the previous designs or elaborations of a previous design, and should not be meaningful or capable of being named; scribbles are not permitted. Only one warning by the supervised is permitted if the subject commits any of the above mistakes. The score in each condition is the number of novel designs produced.

\section{Scoring}

The number of novel designs drawn in each condition formed the score for that condition. The novel design score is the total output minus the sum of [preservative responses + nameable drawings + drawings with the wrong number of lines (only for the fixed condition) + preservative responses including rotations or mirrorimage versions of previous drawings + variations on a theme + complicated drawings that differ from previous ones by small details and scribbles]. There were two components in this test; Digit fluency 1: the novel design score for the free condition and Digit fluency 2: novel design score for the fixed condition. Duration of this test was approximately 12 minutes.

\section{Response inhibition}

Response inhibition is a measure of executive control. The concept refers to the suppression of actions that are not required any more or that are inappropriate, which supports flexible and goal-directed behavior in ever-changing environments. Inhibiting a response involves several prefrontal processes of monitoring and stops a performance to promote controlled behavior [33]. In Stroop test the names of the colour "Blue", "Green", "Red" and "Yellow" are printed in capital letters on a white background but the actual colour of the printed letter does correspond to the name of the colour; occasionally the colour of the print corresponds with the colour designated by the word. This requires a strong degree of response inhibition in the associative cortical areas. The words are printed in 16 rows and 11 columns. The stimulus sheet is placed in front of the subject. The subject is asked to read the word stimuli column-wise as fast as possible. The time taken to read all the 11 columns and the number of errors are noted. Next, the subject is asked to name the colourin which the words are printed. This time also the subject proceeds column wise. The time taken to name all the colours and the number of errors are noted [33]. 
Scoring

The reading time and the naming time were converted into seconds. The reading time was subtracted from the naming time to get the Stroop effect score (Stroop effect score = Time taken to name Time taken to read the words). The time taken to complete this test was 20 minutes. Uncorrected errors were noted down separately for both the phases.

\section{Validity of the tests}

The validity for 'Stroop' and 'Fluency' were established independently for the literate and illiterate samples for Indian population [34].

\section{Pregnancy related anxiety questionnaire (PRAQ)}

Pregnancy related anxieties Questionnaire-Revised version [35] is an abbreviated version of anxiety scale developed originally by Van den Bergh, in 1990. It is used in obstetrics practice or in research as a short measure of the pregnant women's emotional state that refers to her specific fears and worries related to pregnancy and can be used for repeated measurements.

\section{Data-extraction}

This scale consists of ten items that fits into a three-factor model i.e. Fear of giving birth ( 3 items), fear of bearing a physically or mentally handicapped child (4 items) and concern about one's appearance ( 3 items). Women were asked to underline one of the five possible responses closest to their feeling related to her pregnancy [36].

\section{Scoring}

PRAQ has a 5-point scale, ranging from 'never' to 'very often'. Cronbach's alpha of the subscales in different stages of pregnancy were all more than 0.76 [37].

\section{Data analysis}

Statistical analysis was done using SPSS Version 16.0. Chi squared and 'Independent Samples' test were used for baseline comparisons. As the data were not normally distributed, between groups comparisons were done using 'Mann-Whitney U test'.

\section{Results}

Two hundred twenty-eight women who registered for antenatal check up at the center were screened; 146satisfied the selection

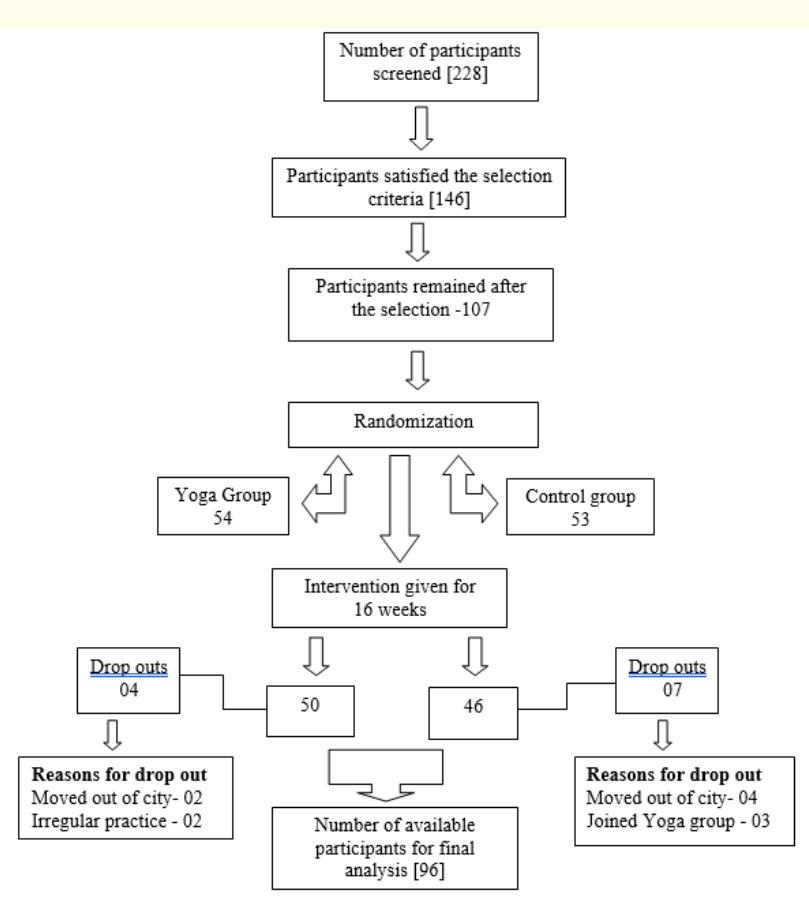

Figure 1: Showing Antenatal RCT profile of the participants recruited in the study.

criteria; 107 women registered and signed the informed consent. There were 11 drop outs during the study period.

The reasons for drop out were: (a) 3 participants in the control group requested for a shift to the yoga group because of the growing awareness about yoga through the media; (b) 6 participants moved out of Bengaluru before 36th week to her parent's town; although this aspect was discussed at the time of recruitment, the women had to oblige to the insistence by the parent's family as a socio-cultural norm in South India; and (c) 2 participants, who did not practice regularly ( $>50 \%$ of missing days).

Demographic characteristics are shown in table 2. The baseline values of the two groups were matched on all variables $(p>0.05$, Independent Samples ' $t$ ' test and Chi-square test). The two groups were matched for all baseline characteristics excluding professional status (i.e., housewife or working outside the home). BMI was less than 25.6 in both groups. Obese women were excluded and there were none who were underweight. None of the women in either group were smokers. 


\begin{tabular}{|c|c|c|c|c|c|c|c|c|c|c|c|c|}
\hline \multirow{4}{*}{ Variables } & & & \multirow{2}{*}{ Age } & \multirow{2}{*}{$\begin{array}{l}\text { Height } \\
\text { (Inches) }\end{array}$} & \multirow{2}{*}{$\begin{array}{c}\text { Gravida } \\
\\
\text { G1 } \\
\text { (Prima) }\end{array}$} & \multirow[b]{2}{*}{$\begin{array}{c}\text { G2 } \\
\text { (Secunda 2) }\end{array}$} & \multirow{2}{*}{$\begin{array}{c}\text { Occupation } \\
\text { Working }\end{array}$} & & \multicolumn{2}{|c|}{ Wt (kgs) } & \multicolumn{2}{|c|}{$\begin{array}{c}\text { BMI } \\
\text { (Body mass } \\
\text { index) }\end{array}$} \\
\hline & & & & & & & & $\begin{array}{c}\text { Not } \\
\text { working } \\
\text { /House } \\
\text { wives }\end{array}$ & $\begin{array}{c}\text { Pre } \\
\left(20^{\text {th }}\right. \\
\text { weeks })\end{array}$ & $\begin{array}{c}\text { Post } \\
\left(36^{\text {th }}\right. \\
\text { weeks })\end{array}$ & $\begin{array}{c}\text { Pre } \\
\left(20^{\text {th }}\right. \\
\text { week })\end{array}$ & $\begin{array}{c}\text { Post } \\
\left(36^{\text {th }}\right. \\
\text { week })\end{array}$ \\
\hline & $\begin{array}{c}\text { Yoga } \\
(\mathrm{N}=50)\end{array}$ & $\begin{array}{c}\text { Mean } \pm \\
\text { S.D }\end{array}$ & $\begin{array}{c}26.41 \pm \\
3.01\end{array}$ & $\begin{array}{c}63.67 \pm \\
1.81\end{array}$ & $\begin{array}{c}45 \\
(88 \%)\end{array}$ & $5(12 \%)$ & $32(65 \%)$ & $18(35 \%)$ & $\begin{array}{c}63.69 \pm \\
9.67\end{array}$ & $\begin{array}{c}71.82 \pm \\
9.90\end{array}$ & $\begin{array}{r}24.97 \\
\pm 3.52\end{array}$ & $\begin{array}{l}28.54 \\
\pm 3.60\end{array}$ \\
\hline & $\begin{array}{c}\text { Control } \\
(\mathrm{N}=46)\end{array}$ & $\begin{array}{c}\text { Mean } \pm \\
\text { S.D }\end{array}$ & $\begin{array}{c}24.96 \pm \\
2.58\end{array}$ & $\begin{array}{c}62.84 \pm \\
1.98\end{array}$ & $\begin{array}{c}40 \\
(87 \%)\end{array}$ & $6(13 \%)$ & 22 (49\%) & $24(51 \%)$ & $\begin{array}{c}61.56 \pm \\
8.56\end{array}$ & $\begin{array}{c}69.91 \pm \\
8.84\end{array}$ & $\begin{array}{r}25.05 \\
\pm 3.80\end{array}$ & $\begin{array}{l}28.55 \\
\pm 3.86\end{array}$ \\
\hline
\end{tabular}

Table 2: Demographic characteristics of the subjects.

Group means and SD of all participant variables; all $20^{\text {th }}$ week (= Pre) except where stated Post $\left(=36^{\text {th }}\right.$ week). No difference between groups was statistically significant on any Pre or Post variable (Gravidae and Occupation: Chi square test; others independent samples' $t$ ' test.) G1- Prima, G2- Secunda 2, W- Working, HW-Housewife, Wt- Weight, BMI- Body Mass Index.

Primary variables

\begin{tabular}{|c|c|c|c|c|c|c|c|c|c|c|c|}
\hline \multirow{3}{*}{\multicolumn{2}{|c|}{ Variables }} & \multirow{4}{*}{ 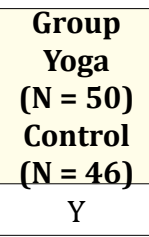 } & \multicolumn{3}{|c|}{ Pre } & \multicolumn{3}{|c|}{ Post } & \multicolumn{2}{|c|}{ Pre-post } & \multirow{3}{*}{$\begin{array}{c}\text { Significance } \\
\text { level (p) }\end{array}$} \\
\hline & & & \multirow{3}{*}{$\begin{array}{c}\text { Mean } \pm \text { SD } \\
13.53 \pm 2.94\end{array}$} & \multicolumn{2}{|c|}{ CI } & \multirow{2}{*}{ Mean \pm SD } & \multicolumn{2}{|c|}{ CI } & \multirow{2}{*}{ ES } & \multirow{2}{*}{$\begin{array}{c}\% \\
\text { change }\end{array}$} & \\
\hline & & & & LB & UB & & LB & UB & & & \\
\hline \multirow{8}{*}{ Fluency } & \multirow{2}{*}{$\mathrm{PF}$} & & & 12.71 & 14.36 & $17.89 \pm 3.40^{* * *}$ & 16.93 & 18.85 & 1.64 & 32.16 & \multirow{2}{*}{$\mathrm{p}<0.001$} \\
\hline & & $\mathrm{C}$ & $13.48 \pm 1.24$ & 13.11 & 13.86 & $15.30 \pm 2.88$ & 14.44 & 16.17 & 0.76 & 13.48 & \\
\hline & \multirow{2}{*}{$\mathrm{CF}$} & $\mathrm{Y}$ & $15.98 \pm 2.22$ & 15.36 & 16.61 & $20.14 \pm 3.68^{* * *}$ & 19.10 & 21.17 & 1.23 & 26.03 & \multirow{2}{*}{$\mathrm{p}<0.001$} \\
\hline & & $\mathrm{C}$ & $15.93 \pm 1.53$ & 15.47 & 16.39 & $17.47 \pm 2.25$ & 16.79 & 18.14 & 0.74 & 9.60 & \\
\hline & \multirow{2}{*}{$\begin{array}{c}\text { DF } \\
\text { I- Free }\end{array}$} & $\mathrm{Y}$ & $13.31 \pm 2.80$ & 14.10 & 14.10 & $18.88 \pm 3.96^{* * *}$ & 20.00 & 20.00 & 1.69 & 41.85 & \multirow{2}{*}{$\mathrm{p}<0.001$} \\
\hline & & $\mathrm{C}$ & $13.07 \pm 2.65$ & 13.86 & 13.86 & $15.20 \pm 2.78$ & 16.03 & 16.03 & 0.99 & 16.30 & \\
\hline & \multirow{2}{*}{$\begin{array}{c}\text { DF } \\
\text { II- } \\
\text { Fixed }\end{array}$} & $\mathrm{Y}$ & $21.80 \pm 6.17$ & 23.54 & 23.54 & $29.22 \pm 8.69^{* *}$ & 31.66 & 31.66 & 0.80 & 33.99 & \multirow{2}{*}{$\mathrm{p}<0.01$} \\
\hline & & $\mathrm{C}$ & $21.09 \pm 3.41$ & 22.11 & 22.11 & $24.33 \pm 3.87$ & 25.50 & 25.50 & 0.88 & 15.36 & \\
\hline \multirow{4}{*}{$\begin{array}{l}\text { Stroop test } \\
\text { (Response } \\
\text { Inhibition) }\end{array}$} & \multirow{2}{*}{$\begin{array}{l}\text { Stroop } \\
\text { Effect }\end{array}$} & $\mathrm{Y}$ & $108.31 \pm 16.46$ & 103.68 & 112.94 & $83.24 \pm 14.96^{* * *}$ & 79.03 & 87.44 & 1.43 & 23.16 & \multirow{2}{*}{$\mathrm{p}<0.001$} \\
\hline & & $\mathrm{C}$ & $108.33 \pm 16.27$ & 103.44 & 113.22 & $98.33 \pm 19.63$ & 92.44 & 104.23 & 0.74 & 9.23 & \\
\hline & \multirow{2}{*}{$\begin{array}{l}\text { Stroop } \\
\text { Error }\end{array}$} & $\mathrm{Y}$ & $4.12 \pm 0.65$ & 3.93 & 4.30 & $1.92 \pm 1.51^{*}$ & 1.50 & 2.35 & 1.75 & 53.40 & \multirow{2}{*}{$\mathrm{p}<0.05$} \\
\hline & & $\mathrm{C}$ & $4.09 \pm 0.70$ & 3.88 & 4.30 & $2.60 \pm 0.91$ & 2.15 & 2.33 & 2.15 & 36.40 & \\
\hline \multirow{2}{*}{\multicolumn{2}{|c|}{ PRAQ }} & $\mathrm{Y}$ & $26.88 \pm 5.35$ & 25.38 & 28.39 & $18.45 \pm 4.33^{* * *}$ & 17.23 & 19.67 & 17.23 & 31.36 & \multirow[t]{2}{*}{$\mathrm{p}<0.001$} \\
\hline & & $\mathrm{C}$ & $27.64 \pm 4.57$ & 26.27 & 29.02 & $23.20 \pm 6.31$ & 21.30 & 25.10 & 21.30 & 16.06 & \\
\hline
\end{tabular}

Table 3: Showing Mean \pm SD, CI, Percentage changes and Level of significance of all variables between the groups. ${ }^{* * *} \mathrm{p}<0.001 ;{ }^{* *} \mathrm{p}<0.01$ and ${ }^{*} \mathrm{p}<0.05$, comparing the variables between the groups using 'Mann Whitney U test'.

Y: Yoga, C: Control, PF: Phonemic Fluency, CF: Category Fluency (Animal Names), DF: Design Fluency, PRAQ: pregnancy related anxiety Questionnaire, CI: Confidence Interval, UB: Upper Bound/ LB: Lower Bound. Legend: Yoga group shows significantly better improvements than control group on all three components of fluency test. 
There were no significant differences between the two groups ( $p>0.05$, Mann Whitney $U$ test) in their baseline scores on all variables.

Results after intervention: Fluency tests

The Phonemic Fluency showed significantly better increase in yoga (32.16\%) group than the control group (13.48\%) with significant difference between groups $\mathrm{p}<0.001$ with an effect size of 1.64 in the yoga group and 0.76 in the control group.

There was also significant improvement in Category fluency (animal names) in both groups;26.03\% (effect size 1.23) in yoga and $9.60 \%$ (effect size 0.74 ) in control group with significant difference between groups at $\mathrm{p}<0.001$.

The Design fluency I (Free condition) test also improved in yoga by $41.85 \%$ (effect size 1.69) and in control group by $16.30 \%$ (effect size 0.99 ) with significant difference between groups at $\mathrm{p}<0.001$. There was a similar improvement in Design fluency II (fixed condition) Test (effect size of 0.80 in the Yoga group and 0.88 in the controls) with significant difference between groups at $\mathrm{p}<0.01$.

\section{Response inhibition - Stroop test}

Stroop effect showed significant improvements within both groups; $23.16 \%$ (effect size of 1.43) in the yoga group and 9.23\% (effect size of 0.74 ) in the control group. Mann Whitney test showed significant difference between groups at $\mathrm{p}<0.001$.

Stroop Error also reduced significantly in yoga $(53.40 \%$, effect size 1.75) group as compared to control group (36.40\%, effect size 2.15 ) with significant difference between groups at $\mathrm{p}<0.05$.

Pregnancy related anxiety questionnaire (PRAQ)

Scores of pregnancy related anxiety reduced in yoga group by $31.36 \%$ compared to control group (16.06\%) with significant difference between groups at $\mathrm{p}<0.001$.

Spearman's coefficient correlation test showed no significant correlation between anxiety and any of the variables that measured the cognitive functions.

\section{Discussion}

This randomized two armed active control study has shown that there were significantly better improvements in the yoga group as compared to antenatal exercise group in all three components of fluency tests (Verbal, Category and Design fluencies) and Response inhibition test (Stroop test) along with significant reduction in pregnancy related anxiety.

\section{Comparisons}

To the best of our knowledge this is the first study on the effect of yoga on cognitive functions during pregnancy. Studies on yoga in normal healthy volunteers have been found to be effective in improving many cognitive functions such as memory and attention tasks. Performance on six letter cancellation task (SLCT) which requires selective attention, concentration, visual scanning abilities, and a repetitive motor response was studied before and after a meditation technique called cyclic meditation (CM) in healthy volunteers in a self as control design with significantly higher scores after sessions of CM (24.9\%) than after supine rest sessions (13.6\%) [38]. Further, a report from the same lab in 2009 (Patra and Telles) showed significant increase in scores on digit letter substitution test (DLST), letter-copying and circle-dotting tasks after CM, suggesting better information processing [39]. Chattha., et al. showed improvement in cognitive functions (remote memory, verbal retention and recognition, and delayed and immediate recall) in perimenopausal women after 8 weeks of integrated yoga in a randomized control active control study [40]. Patients with major depression who practiced Sahaja yoga showed greater degree of improvement in executive functions like manipulation of information in the verbal working memory (Reverse digit span test) and attention span (SLCT) than those who had only anti-depressant medication [41].

\section{Mechanism}

During pregnancy, profound changes occur in stress adaptation mechanisms that are involved in 'flight and fight system'. Although these changes are essential for healthy progression of pregnancy, heightened stress responses not only offer high risk to the health of the mother and fetus, but also affect her cognitive functions. Hypothalamo Pituitary Adrenal (HPA) axis, sympathetic-adrenalmedullary system (SMS) and changes in several neurotransmitter systems within the brain appear to be the mediators of these changes during stress. Heightened levels of adrenalin, noradrenalin and gluco-corticoids have been implicated. Although the entry of these hormones is restricted by blood-brain barrier, studies have shown their influence on cerebral functions [42]. Excess stress also affects the dopaminergic projections from ventral tegmental area 
to prefrontal and anterior cingulate cortices $[43,44]$ and the prefrontal glutamatergic system [45] and these are known to influence the cognitive functions.

Yogic techniques including relaxation techniques are found to improve sympatho-vagal balance by reducing the sympathetic tone in normal volunteers [46]. A two-day yoga programme which involved relaxation technique decreased occupational stress levels and baseline autonomic arousal [47]. Yoga improved the amount of slow wave sleep following the practice of yoga based relaxation techniques twice a day [48] suggesting enhancement in quality of sleep. It is well documented that a healthy sleep is necessary for improving various cognitive functions such as memory and learning processes [49]. More directly yoga and massage therapy programme was found to be effective in symptom reduction and general health improvement in a variety of conditions that are relevant to pregnancy, such as anxiety, depression, back pain, and stress [50]. Moreover, a preliminary research from a mindfulness-based childbirth and parenting education through a traditional mindfulness-based stress reduction program found improvements in measures of anxiety, depression, and positive affect in women participating in their third trimester of pregnancy [51]. A recent study by Teper et al has shown greater degree of executive control in the participants who were practicing meditation [52]. We reported a significant improvement in heart rate variability frequency spectra after regular practice of yoga during normal pregnancy. There was significant reduction in low frequency spectrum and the ratio of low and high frequency spectra suggesting improvement in autonomic adaptive responses to stress [53].

Electrophysiological studies during cognitive functions in healthy volunteers have reported increase in peak amplitude with reduction in latency of $\mathrm{P} 300$ wave (a positive wave that occurs at $300^{\text {th }}$ millisecond in the auditory evoked potentials in EEG tracing) after cyclic meditation [54] indicating better information processing speed and increased activation of attentional resourcesin hippocampus and other prefrontal associated areas after CM [55].

Thus, it may be hypothesized that the improvement in the executive functions observed in this study is due to the effect of yoga in bringing about better information processing in the subtle layers of the prefrontal cortex. This in turn could be due to reduction of stress following the alert full rest that yoga offers.
Strengths of the study

The strengths of this study were: (a) its randomized design in which there was an active control group, (b) good sample size, and (c) the first evidence on the benefits of yoga on cognitive functions during pregnancy. We may thus recommend that yoga may be included to all antenatal programs.

Limitations of the study were: (a) some interaction between the two groups may have occurred although attempt was made to keep them away; (b) no correlation could be demonstrated between the changes in scores on anxiety and cognitive functions after yoga although we hypothesized that the benefits could be due to reduction in stress. This could be due to the type of questions in PRAQ or due to the sample size.

\section{Conclusion}

This study showed that integrated antenatal yoga starting from second trimester helps in improving cognitive functions and reducing anxiety suggestive of a positive impact of yoga in promoting better information processing in prefrontal cortex.

\section{Suggestions for Future Work}

In future studies, these inexpensive yoga techniques may be tried in different cultures for self-management of their excessive stress and anxiety during pregnancy. Such studies would throw more light on the generalizability of yoga practice and the reproducibility of the effects of yoga worldwide. Long term follows up of the off springs of these two groups would throw light on the positive effects of yoga on the fetus.

\section{Acknowledgement}

We are thankful to all staff and consultants of Maiya multi-specialty hospital and all participants for their cooperation during the project. We thank Dr Balaram Pradhan for conducting the statistical analysis of the data.

\section{Financial Support}

This project was funded by S-VYASA University.

\section{Bibliography}

1. Danel I., et al. "Magnitude of maternal morbidity during labour and delivery: United States, 1993-1997". American Journal of Public Health 93 (2003): 631-634. 
2. Groot RD., et al. "Memory performance, but not information processing speed, may be reduced during early pregnancy". Journal of Clinical and Experimental Neuropsychology 25 (2003): 482-8

3. Crawley RA., et al. "Cognition in pregnancy and the first year post-partum". Psychology and Psychotherapy 76 (2003): 69-84.

4. Onyper SV., et al. "Executive functioning and general cognitive ability in pregnant women and matched controls". Journal of Clinical and Experimental Neuropsychology 32 (2010): 986995.

5. Mennes M., et al. "Long-term cognitive sequelae of antenatal maternal anxiety: involvement of the orbitofrontal cortex". Neuroscience and Biobehavioral Reviews 30 (2006): 10781086.

6. Elfgren CI and Risberg J. "Lateralized frontal blood flow increases during fluency tasks: influence of cognitive strategy". Neuropsychologia 36 (1998): 505-512.

7. Robinson H., et al. "Neuroanatomical correlates of executive functions: a neuropsychological approach using the EXAMINER battery". Journal of the International Neuropsychological Society 20 (2014): 52.

8. Sarkis RA., et al. "Predictors of decline in verbal fluency after frontal lobe epilepsy surgery". Epilepsy and Behavior 27 (2013): 326-329.

9. Kramer J and Kaplan E. "Verbal and design fluency in patients with frontal lobe lesions". Journal of the International Neuropsychological Society 7 (2001): 586-596.

10. Robinson G., et al. "The differing roles of the frontal cortex in fluency tests". Brain 135 (2012): 2202-2014.

11. Osório CM., et al. "Neuropsychological functioning and brain energetics of drug resistant mesial temporal lobe epilepsy patients". Epilepsy Research 138 (2017): 26-31.

12. Stuss DT., et al. "Stroop performance in focal lesion patients: dissociation of processes and frontal lobe lesion location". Neuropsychologia 39 (2001): 771-786.

13. Lee DY., et al. "Neural correlates of the stroop test performance in patients with Alzheimer's disease: A FDG-PET study”. Alzheimer's and Dementia: Journal Alzheimer Disease and Associated 4 (2011): S75.
14. MacDonald AW., et al. "Dissociating the role of the dorsolateral prefrontal and anterior cingulate cortex in cognitive control". Science 288 (2000): 1835-1838.

15. Cardwell MS. "Stress: pregnancy considerations". Obstetrical and Gynecological Survey 68 (2013): 119-129.

16. Kubo A., et al. "Yoga for heart failure patients: a feasibility pilot study with a multiethnic population". International Journal of Yoga Therapy 21 (2011): 77-83.

17. Pandya DP., et al. "Mind-body therapy in the management and prevention of coronary disease". Comprehensive Therapy 25 (1999): 283-293.

18. Patra S and Telles S. "Heart rate variability during sleep following the practice of cyclic meditation and supine rest". Association for Applied Psychophysiology and Biofeedback 35 (2010): 135-140.

19. Wirshing DA., et al. "The effects of novel antipsychotics on glucose and lipid levels". The Journal of Clinical Psychiatry (2002): 63.

20. Michalsen A., et al. "Iyengar yoga for distressed women: a 3-armed randomized controlled trial". Evidence-Based Complementary and Alternative Medicine (2012).

21. Hartfiel N., et al. "Yoga for reducing perceived stress and back pain at work". Occupational Medicine 62 (2012): 606-612.

22. Shim CS and Lee YS. "Effects of a Yoga-focused Prenatal Program on Stress, Anxiety, Self Confidence and Labour Pain in Pregnant Women with In Vitro Fertilization Treatment". Journal of Korean Academy of Nursing 42 (2012): 69-76.

23. Babbar S., et al. "Yoga during pregnancy: a review". American Journal of Perinatology 29 (2012): 459-464.

24. Chuntharapat S., et al. "Yoga during pregnancy: effects on maternal comfort, labor pain and birth outcomes". Complementary Therapies in Clinical Practice 14 (2008): 105-115.

25. Smith CA., et al. "Acupuncture or acupressure for pain management in labour (Cochrane Review)". Cochrane Library (2011).

26. Beddoe AE., et al. "Effects of mindful yoga on sleep in pregnant women: a pilot study". Biological Research for Nursing 11 (2010): 363-370.

27. Nagarathna R. "Yoga for a healthy lifestyle". Gaia Books (1990). 
28. Davies GA., et al. "Joint SOGC/CSEP clinical practice guideline: exercise in pregnancy and the postpartum period". Canadian Journal of Applied Physiology 28 (2003): 329-341.

29. Spreen $O$ and Strauss E. "A compendium of neuropsychological tests: Administration, norms, and commentary". Oxford University Press (1998).

30. John PJ. "Neuropsychological and spectral EEG correlates of dimensions of schizophrenia". Unpublished MD thesis submitted to National Institute of Mental Health and Neuroscience, Bangalore, India (1998).

31. Lezak MD., et al. "Neuropsychological assessment". Oxford University Press, USA (2004).

32. Jones-Gotman M and Milner B. "Design fluency: The invention of nonsense drawings after focal cortical lesions". Neuropsychologia 15 (1977): 653-674.

33. Verbruggen $\mathrm{F}$ and Logan GD. "Response inhibition in the stopsignal paradigm”. Trends in Cognitive Sciences 12 (2008): 418424.

34. Rao SL., et al. "Nimhans Neuropsychology battery". NIMHANS, Bangalore, India $1^{\text {st }}$ edn: (2004).

35. Huizink AC. "Prenatal stress and its effect on infant development". Doctoral dissertation Utrecht University. The Netherlands: (2000).

36. Huizink AC., et al. "Is pregnancy anxiety a distinctive syndrome?". Early Human Development 79 (2004): 81-91.

37. Huizink AC., et al. "Stress during pregnancy is associated with developmental outcome in infancy". Journal of Child Psychology and Psychiatry 44 (2003): 810-818.

38. Sarang P and Telles S. "Effects of two yoga based relaxation techniques on heart rate variability (HRV)". International Journal of Stress Management 13 (2006): 460.

39. Pradhan B and Nagendra HR. "Immediate effect of two yogabased relaxation techniques on attention in children". International Journal of Yoga 3 (2010): 67.

40. Pradhan B and Nagendra HR. "Normative data for the digitletter substitution task in school children". International Journal of Yoga 2 (2009): 69-72.

41. Chattha R., et al. "Effect of yoga on cognitive functions in climacteric syndrome: a randomised control study". BJOG 115 (2008): 991-1000.
42. Sharma VK., et al. "Effect of Sahaj Yoga on neuro-cognitive functions in patients suffering from major depression". Indian Journal of Physiology and Pharmacology 50 (2006): 375-383.

43. McGaugh JL and Roozendaal B. "Role of adrenal stress hormones in forming lasting memories in the brain". Current Opinion in Neurobiology 12 (2002): 205-210.

44. Abercrombie ED., et al. "Differential effect of stress on in vivo dopamine release in striatum, nucleus accumbens, and medial frontal cortex". Journal of Neurochemistry 52 (1989): 16551658.

45. Steciuk M., et al. "Immobilization-induced glutamate efflux in medial prefrontal cortex: blockade by (+)-Mk-801, a selective NMDA receptor antagonist". Stress 3 (2000): 195-199.

46. Patra S and Telles S. "Positive impact of cyclic meditation on subsequent sleep". Medical Science Monitor 15 (2009): CR37581.

47. Sarang P and Telles S. "Effects of two yoga based relaxation techniques on heart rate variability (HRV)". International Journal of Stress Management 13 (2006): 460.

48. Patra S and Telles S. "Heart rate variability during sleep following the practice of cyclic meditation and supine rest". Association for Applied Psychophysiology and Biofeedback 35 (2010): 135-140.

49. Smith C and Lapp L. "Prolonged increases in both PS and number of REMS following a shuttle avoidance task". Physiology and Behavior 36 (1986): 1053-1057.

50. Field T., et al. "Yoga and massage therapy reduce prenatal depression and prematurity". Journal of Bodywork and Movement Therapies 16 (2012): 204-209.

51. Duncan LG and Bardacke N. "Mindfulness-based childbirth and parenting education: promoting family mindfulness during the perinatal period". Journal of Child and Family Studies 19 (2010): 190-202.

52. Teper R and Inzlicht M. "Meditation, mindfulness and executive control: the importance of emotional acceptance and brain-based performance monitoring". Social Cognitive and Affective Neuroscience 8 (2013): 85-92.

53. Satyapriya M., et al. "Effect of integrated yoga on stress and heart rate variability in pregnant women". International Journal of Gynecology and Obstetrics 104 (2009): 218-222. 
54. Sarang SP and Telles S. "Changes in P300 following two yogabased relaxation techniques". International Journal of Neuroscience 116 (2006): 1419-1430.

55. Sarang SP and Telles S. "Immediate effect of two yoga-based relaxation techniques on performance in a letter-cancellation task". Perceptual and Motor Skills 105 (2007): 379-385.

\section{Assets from publication with us}

- Prompt Acknowledgement after receiving the article

- Thorough Double blinded peer review

- Rapid Publication

- Issue of Publication Certificate

- High visibility of your Published work

Website: www.actascientific.com/

Submit Article: www.actascientific.com/submission.php

Email us: editor@actascientific.com

Contact us: +919182824667 